\title{
PENSAMIENTO Y ACCIÓN SOCIOEDUCATIVA EN EUROPA Y ESPAÑA. EVOLUCIÓN DE LA PEDAGOGÍA Y EDUCACIÓN SOCIAL ${ }^{1}$
}

\author{
Fanny T. Añaños-Bedriñana ${ }^{2}$ \\ Universidad de Granada - España \\ Grupo de Investigación HISULA \\ fanntab@ugr.es
}

Recepción: 27/01/2012

Evaluación: 15/02/2012

Aceptación: 29/05/2012

Artículo de Reflexión

doi: 10,9757

\section{RESUMEN}

El artículo tiene como objeto ofrecer, por un lado, un marco de desarrollo histórico tanto en Europa, especialmente en Alemania, como en España; por otro, un espacio teórico epistemológico y referencial bajo el amparo de las corrientes actuales de la Pedagogía y Educación Social.

Al mismo tiempo, aspira incidir en los fundamentos de la Pedagogía y de la Educación Social, puesto que conllevan luces y sombras, planteando la respuesta mediante la acción socioeducativa a partir de la reflexión basada en la praxis, en las evidencias,... sin perder el ideal educativo y el sentido de erigirse como liberadora de la humanidad, orientada a la mejora/transformación de la calidad de vida...
El devenir histórico y en la actualidad nos visibiliza que la Pedagogía Social es una ciencia en constante construcción, abierta y en evolución, que se adapta a las características y peculiaridades del contexto, de las personas y del momento, en el intento de dar respuestas a los desafíos, a las problemáticas concretas o, para promocionar a la población "normalizada", con el fin de promover el cambio y mejorar la calidad de vida.

Palabras clave: Revista Historia de la Educación Latinoamericana, Pedagogia, Educación Social, Historia de la educación, epistemología, campos de Intervención.

\footnotetext{
Proyecto financiado por el Ministerio de Ciencias e Innovación, Proyecto de Investigación Ref. EDU2009-13408, España

2 Doctora en Pedagogía. Profesora Titular de la Universidad de Granada. Dirección: Facultad de CC. EE., Campus Universitario de Cartuja s/n C.P. 18071, Granada, España. Grupos de investigación: "OTRAS. Perspectivas Feministas en Investigación Social", Historia y Prospectiva de la Universidad Latinoamericana HISULA, adscrito a la Universidad Pedagógica y Tecnológica de Colombia. Artículo vinculado al proyecto de investigación la Universidad en la capacitación de maestras rurales en Colombia y Guatemala SGI 1034 y proyecto Historias de vida. Maestras rurales de mediados del siglo XX y XXI en la zona cundiboyacense SGI 980 del grupo de investigación HISULA - UPTC.
} 


\section{FROM IDEA TO ACTION TOWARDS SOCIAL EDUCATION IN EUROPE. EVOLUTION OF PEDAGOGY AND SOCIAL EDUCATION}

\section{ABSTRACT}

This article aims offering on one side: a historical development framework in Europe specially in Germany as well as in Spain; and by another side: A theorical space -Going from Scientific methods and references outlined by today's tendency on pedagogy and social education.

It also craves to understand the origins of pedagogy and social studies at the same time, thus they bring both black and grey ideas for answering through social- educational action based on praxis and evidence without missing the educational plan and sense of human liberation perspective, education oriented towards life quality transformation.

What History became into today's social education awareness, and pedagogy as a science in constant evolution, opened to new approaches brought from features and details of each context either from people or moment of time, as an attempt to accomplish challenges, to specific issues or to promote regular educators aiming for changes and quality life improvement.

Key words: Journal of Latin American Education History, pedagogy, social education, history of education, epistemology, intervention fields.

\section{PENSAMENTO E AÇÃO EDUCATIVA \\ NA EUROPA E ESPAN̉HA. EVOLUÇÃO DA PEDAGOGIA E EDUACION SOCIAL}

\section{RESUMO}

$\mathrm{O}$ artigo tem como objeto oferecer, por um lado, um marco do desenvolvimento histórico tanto na Europa, especialmente na Alemanha, como na Espanha; por outro lado, um espaço teórico - epistemológico e referencial sob o amparo das correntes atuais da Pedagogia e Educação Social.

Ao mesmo tempo, aspira incidir nos fundamentos da Pedagogia Social e da Educação Social, por projetar luzes e sombras, trazendo a resposta mediante a ação socioeducativa a partir da reflexão baseada na práxis, nas evidências,... sem perder o ideal educativo e o sentido de erigir-se como libertadora da humanidade, orientada à melhora e transformação da qualidade de vida..

O devir histórico e a atualidade nos torna visível que a Pedagogia Social é uma ciência em constante construção, aberta e em evolução, que se adapta às características e peculiaridades do contexto, das pessoas e do momento, com a intenção de dar respostas aos desafios, às problemáticas concretas ou, para promover a população "normalizada", com o objetivo de proporcionar a mudança e melhorara qualidade de vida.

Palavras-chave: Revista História Latinoamericana de Educação, educação, educação social, história da educação, epistemologia, campos de intervenção.

\section{INTRODUCCIÓN}

En sus orígenes la Pedagogía Social ha estado vinculada a las prácticas de asistencia a la población más necesitada o problemática, realizadas por instituciones de benevolencia o caridad, especialmente la iglesia católica, pero, tras la segunda guerra mundial, es el Estado de Bienestar junto a las corrientes educadoras los que redefinen y asumen esas responsabilidades como parte de sus obligaciones, en el afán de garantizar a la población general unas prestaciones y servicios básicos.

La educación cobra nuevas dimensiones en el actual contexto del proceso mundial globalizador y postmoderno que exige cambios sustanciales en el currículum, en las formas de enseñanza-aprendizaje, en los estilos de 
relación e intervención, en los contenidos y en los lenguajes de intercambio. Se necesitan esquemas claros, libertad y disponibilidad profesional para reorganizar los saberes especializados de forma que permitan a los educandos comprender la realidad que nos afecta a todos / as y que posibilite la protección y el desarrollo de lo fundamental y de la capacidad de decidir sobre los temas que tienen repercusiones importantes sobre nuestras vidas.

Tanto la Pedagogía Social (PS) como la Educación Social (ES) se ofrecen a esta sociedad como una de las mejores y posibles respuestas, puesto que desde el principio, por vocación y más allá de las corrientes de interpretación, nacieron ambas como saberes teóricos y prácticos cuyo destino era y es el servicio a los seres humanos. La actual profesión denominada Educación Social, cuya matriz esencial es la Pedagogía Social, se convierte en la esperanza educativa, la vía para conquistar un futuro mejor y más digno, no sólo de los excluidos y de los colectivos con alguna problemática sino también de personas "normalizadas" buscando su participación, promoción, desarrollo, etc.

\section{Antecedentes históricos de la Pedagogía Social (PS)}

En el caso de la PS se puede afirmar que se trata de una ciencia joven cuya aparición en el mundo de las ciencias de la educación data un de un poco más de 150 años; no obstante, su estabilización se puede situar en la segunda mitad del siglo XX.

La PS en cuanto ciencia teórica y práctica, nació en Centroeuropa y más en concreto en Alemania, en medio de cambios sociales producidos por el advenimiento de la industrialización y de una revolución de la concepción de la educación que se descentró de los valores tradicionales para ir hacia otros nuevos de la llamada sociedad del proletariado y de las masas.

En la evolución no podemos obviar que antes de la ciencia existen los hechos, es decir, con anterioridad a la reflexión teórica denominada PS, habían personas e instituciones de diferentes ideologías y formación que realizaron en Europa y en América auténticos planteamientos y acciones educativos-sociales, pero éstos no hacían referencias explícitas a la acepción, los principios o a la significación tal como lo conocemos hoy. Por ejemplo, entre otros, la acción social de la Iglesia Católica a lo largo de muchos siglos con los menores abandonados, encarcelados, personas mayores, pobres, escuelas parroquiales, etc.

A grandes rasgos, la situación social en Centroeuropa, a mediados del siglo XIX, nos sitúa con una sociedad en transición de la vida centrada 
en la cultura agrícola (vida tranquila, enraizada, con tradiciones seculares mantenidas y trasmitidas de padres a hijos, con un valor muy grande otorgado a la familia y al orden) a una cultura del trabajo en la industria naciente (fenómeno llamado industrialización). En ésta, entre otros, se produjo un ambiente social caracterizado por la inseguridad e injusticia social, donde la mayor parte requiere ayuda y reclama (el proletariado), a través de revueltas sociales, un cambio hacia una mayor seguridad. Se puede afirmar que es una sociedad en crisis, dando lugar al llamado fenómeno de masas.

En este contexto, había también pensadores y educadores que comenzaron a concebir la educación de otro modo, no tanto centrada en lo individual sino en lo social. A este hecho contribuyó en gran medida la consideración de la situación de las masas proletarias, fenómeno que dio lugar a la aparición del comunismo, bajo la inspiración de Carlos Marx ${ }^{3}$. Refiriéndose a la educación, desde el punto de vista filosófico, sobresalen Marx, Hegel, Natorp, Kant, entre los más destacados, y desde el punto de vista práctico Pestalozzi en Suiza.

Tocqueville, Kierkegaard, Burckhardt y Nietzsche, por ejemplo, empiezan a describir los cambios sociales, desde una perspectiva pesimista, aludiendo que la vida moderna destruiría los ideales y valores de las sociales. En cambio, Tönnies ${ }^{4}$ y Durkheim ${ }^{5}$, hacen una aproximación más mesurada, donde el primero, en 1887 publicó “Comunidad y asociación”, en el que analiza la transformación de la organización social y los efectos de los mismos; el segundo, distinguía también entre dos tipos de sociedad: sociedades premodernas (tradicionales) y sociedades modernas (carentes de cohesión mecánica y natural, individualista, conductas anormales -suicidio-, enferma -anomia-, etc.), en cuyo planteamiento defendía una nueva regulación moral de la sociedad, rigorosa y laica, a la vez.

3 Karl Heinrich Marx, llamado también Carlos Marx (Tréveris, Reino de Prusia, 5 de mayo de 1818 - Londres, Reino Unido, 14 de marzo de 1883), fue un intelectual y militante comunista alemán de origen judío. Considerado el padre del socialismo científico, del comunismo moderno y del marxismo. Sus escritos más conocidos son el Manifiesto del Partido Comunista (con Engels) y el libro El Capital. Tras su muerte sus ideas y la ideología del marxismo comenzaron a ejercer una gran influencia sobre los movimientos socialistas.

4 Ferdinand Tönnies (1855-1936), Sociólogo alemán, estudió filosofía, filología, economía e historia. En 1910 fundó en colaboración con Max Weber y George Simmel la Asociación Alemana de Sociología, de la cual llegó a ser presidente. Su obra más conocida "es Comunidad y Sociedad" (1887), posteriormente la reelabora y hoy se utiliza más la versión de 1912.

5 Emile Durkheim (1858-1917), Francés, Diplomado en filosofía, Profesor de Liceo y Universidad de Burdeos y en La Sorbona (París). Creó la revista L“Année sociologique, fundador de la Escuela francesa de sociología ocupando la primera cátedra de Sociología en la Universidad. De su obra destacamos, además de "De la división del trabajo social" (1893 -tesis doctoral-), "Las reglas del método sociológico" (1895) y "El suicidio" (1897). 
Según Alfonso Moreno ${ }^{6}$ la aportación más importante de Tönnies se halla en el establecimiento de una tipología de sociedades (algo que también plateó Spencer), insertando en cada una de ellas unas características diferenciales con respecto de la otra, y dándole además, una perspectiva histórico-evolutiva lineal, ya que sitúa ambos tipos en un continuum temporal. Otra aportación es la que hace referencia al aspecto valorativo que establece del proceso; al respecto expresa sus dudas sobre la "asociación" o sociedad, representada para él en el capitalismo sea lo mejor. Es el primer crítico con respecto de la idea de progreso.

Por su parte, las contribuciones más destacadas de Durkheim sobre el análisis del cambio social $\operatorname{son}^{7}$ : a) Introdujo en su análisis la perspectiva moral, donde se propone que la fuente trascendental de lo "a priori" de la acción moral es la sociedad, cuya existencia es, a la vez, anterior y posterior a la de cualquiera de sus miembros. Pero como no hay sociedad sino sociedades, considera que hay una moral apropiada para cada sociedad y para cada etapa de su desarrollo. Es, pues, relativista, y no se consideraba que la sociedad actual de su época fuera moralmente superior a las anteriores. b) Este "imperativo" llevó a establecer la teoría de que el origen de todo proceso social debe ser buscado en la constitución del medio social interno, en la estructura social. La estructura social es la última referencia analítica (no ontológica ni metafísica) de toda explicación sociológica. Es, pues, la referencia a tomar para explicar los hechos sociales y sus procesos, es decir, el cambio se explica por y en la estructura social. No hay determinismo divino ni determinismo natural, sino social.

Por otro lado, también emergen pensadores (Gustave Le Bon, Gabriel Tarde) que ven con desconfianza, negativa y peyorativamente el ascenso, el crecimiento y reivindicación de las masas, especialmente tras el caso Dreyfus -1894 a 1906-. El carácter aparentemente no racional de la opinión pública, entre otras explicaciones, generó en muchos casos a la elaboración teórica, como reacción, del elitismo, que tuvo sus formulaciones más elaboradas en los italianos Mosca (1896, libro "La clase dirigente") y Pareto $^{8}$ (1916, libro "Tratado de Sociología General”) y en el alemán italianizado Robert Michels (1911, propuso la "Ley de hierro de la oligarquía").

6 Jorge Alfonso Moreno Chávez, Sociología Jurídica a distancia. (Managua: Universidad Centroamericana, 2010)

Moreno Chávez, "Sociologia Jurídica a distancia".

8 Vilfredo Pareto (1848-1923), en su obra "Trattato di Sociología Generale" (1916) define una sociedad como un sistema social (concepto empleado más tarde por Parsons), que a su vez, atraviesa por tres ciclos de equilibrio: desestabilización, desequilibrio y, de nuevo, equilibrio. Su contribución consistió en introducir -bajo la influencia de Gaetano Mosca y su teoría de la clase dominante (Elementos de Ciencia Política, 1896)-, el concepto de élites. 
Sobre las élites, cabe decir, que estaban formadas por aquellos que destacaban en distintos campos particulares de actividad. Su concepción de la historia es cíclica y el cambio social y político lo concibe como el reemplazo cíclico de las élites: ascenso, declive y reemplazo. Considera que el desarrollo histórico lo hacen minorías activas investidas con atributos para dominar a las masas pasivas. En este panorama, la prensa adquiere nuevas dimensiones, quien conformaría en gran medida y de forma creciente la conciencia de las masas.

\section{Hitos principales en el nacimiento y evolución de la Pedagogía Social}

\section{La palabra y surgimiento de la pedagogía social}

La expresión “pedagogía social” fue usada por primera vez en 1844 por Karl Mager", aunque Diesterweg ${ }^{10}$ es el primer autor reconocido, quien publica "Escritos sobre Pedagogía Social" en 1850. Se trata de un uso de la expresión sin mayores afanes científicos o epistemológicos, aludiendo el primero a un género de bibliografía pedagógica y el segundo refiriendo a la utilidad de englobar contenidos y áreas de acción educativas-sociales sin que se usen como resultado de un proceso teórico-sistémico ${ }^{11}$; no obstante en ambos casos con un acento puesto en lo popular y de hecho equipara educación social con "educación popular".

Fueron Willmann ${ }^{12}$, Fischer ${ }^{13}$ y Natorp ${ }^{14}$, los que impulsaron esta nueva ciencia. En Alemania, hacia 1898, apareció publicada la obra de Paul Natorp denominada "Pedagogía Social" 15 . A partir de la cual Natorp es considerado el "padre" de esta ciencia.

\footnotetext{
Karl Mayer, "La Pedagogía Social en Alemania", en Nuevos retos de la Pedagogía Social: la formación del profesorado, Winfried Böhm, (Salamanca: Sociedad Ibérica de Pedagogía Social, 2002), 15-20.

10 Adolph Diesterweg (1790-1866) (cit. por Arroyo, 1985: 206).

11 Gloria Pérez Serrano, Pedagogía Social - Educación Social. Construcción cientifica e intervención práctica. (Madrid: Narcea, 2004).

12 Otto Willmann (1840-1912).

13 Kuno Fischer (1824-1903).

14 Paul Natorp (1854-1924), Filósofo y pedagogo alemán representante de la escuela de Marburgo, que entiende la pedagogía únicamente como social; dio origen a los tratados sistemáticos de pedagogía, influyó en la escuela unificada y la escuela del trabajo, y ha sido la base para el movimiento posterior de la Pedagogía Social. Pretendió un socialismo no marxista y rechazó rotundamente todo lo que no se integrara en la comunidad de hombres. Su imperativo categórico viene a ser el de que se debe obrar de forma que se use la Humanidad como un fin y no como un medio. Relegó la religión al dominio de lo subjetivo e intentó desarraigar su trascendencia.

15 Esta obra referente en el área fue traducida al español por una gran pedagoga española María de Maeztu (1882-1948), y se publica en 1915.
} 
Natorp es un filósofo neokantiano y en su obra se inspiró en las ideas de Platón y Pestalozzi. Para él la PS no es una parte separada de la Educación general sino que es toda la educación, definiendo la Pedagogía como "La ciencia de la educación por la comunidad y para la comunidad"16.

En otras palabras, no tiene sentido hablar de educación individual, puesto que "el individuo es una pura abstracción"; lo que existe es la comunidad. "El hombre sólo se hace hombre por medio de la comunidad", por consiguiente, "la educación es social por naturaleza" - postura que será denominada posteriormente como "sociologismo pedagógico"-, de manera que la expresión PS no tiene de ningún modo el sentido de intervención práctica en el orden de los problemas sociales de las poblaciones, como posteriormente sucederá.

\section{La pedagogía social adquiere una dimensión práctica}

A finales del siglo XX, en Alemania, predomina en PS el tratamiento de ciencia que se ocupa, fundamentalmente, del Trabajo Social con grupos de población que sufren problemas ${ }^{18}$. La dimensión estructural que alcanzan los problemas sociales como el desempleo, la pobreza, la marginalidad, etc., no permiten hacer una interpretación subsidiaria del papel de la sociedad y el Estado, como si de "disfunciones" del sistema social se tratara. Por lo tanto, como ejercicio del deber de la sociedad y el Estado con sus miembros y como exigencia de los derechos de todo ser humano, se hace imprescindible una atención normalizada y universal de carácter socio pedagógico.

A los grandes problemas de la revolución industrial se les van a unir, unos años más tarde, aquellos derivados de la I Guerra Mundial: niños/as huérfanos/ as y abandonados/as, minusválidos/as, falta de escuelas, etc. Ante todo ello surge el llamado "movimiento pedagógico-social" en el intento de dar respuestas educativas a tales situaciones. Se trata de una nueva forma de relacionar la Pedagogía con lo "social" y que le da un contenido práctico-educativo en los años de la llamada República de Weimar en Alemania ${ }^{19}$, momento en que aparecieron educadores seriamente preocupados especialmente por los problemas de la niñez y de la juventud ${ }^{20}$. Uno de los resultados concretos de esta tendencia es la Ley Nacional de Protección a la Juventud que, en la

\footnotetext{
16 Blanco, R. Teoría de la Educación (2 vol). (Madrid: Librería y Casa Editorial de Hernando), (1985).

17 Paul Natorp (1913)

18 José Ma Quintana, “La Pedagogía Social en Italia”, Pedagogía Social, No 4, (1989), 7.

19 Se conoce como República de Weimar a la etapa de la Historia de Alemania que va desde la caída del Imperio en 1918 hasta el ascenso de Hitler al poder en 1933. Es un régimen parlamentario que se construyó en torno a la constitución aprobada en la ciudad de Weimar el 31 de julio de 1919.

20 Matías Bedmar y Fanny Añaños (2006).
} 
Alemania de 1922, viene a respaldar las iniciativas pedagógico-sociales desde las instituciones públicas y privadas ${ }^{21}$.

Para el profesor Arroyo $^{22}$ la figura más representativa de dicho "movimiento" en los años veinte fue Nohl'2 . Entre 1928 y 1933 Nohl y Pallat dirigen y publican una extensa obra en cinco volúmenes llamada "Manual de Pedagogía" en la que el término Pedagogía Social aparece en el último de ellos de la mano de Bäumer ${ }^{24}$. La PS toma aquí un nuevo giro, designando tareas educativas-sociales y estatales que se realizan fuera de la escuela. Dichas tareas educativas se originaron como socorro a las necesidades con el objetivo último de "perseguir el bien del sujeto".

Los rasgos característicos de la filosofía de Nohl son: partir de la realidad para elaborar la teoría de la PS, integración de esfuerzos colectivos en el proyecto educativo y necesidad de modificar las condiciones ambientales para conseguir una mayor eficacia en los programas de PS.

Nohl, apoyándose en la Pedagogía hermenéutica de Dilthey ${ }^{25}$ elabora un concepto de la PS que denomina "Teoría de una práctica para la práctica". Cuestionó la escuela intelectual y abrió así a la PS nuevos campos de trabajo, entendiéndola como una "educación fuera de la escuela y de la familia", que va desde la etapa infantil pasando por la formación juvenil hasta la formación adulta ${ }^{26}$.

La Escuela de Nohl impulsa decididamente el desarrollo de la PS, tanto en sus aspectos teóricos como fundamentalmente prácticos. La concibe por vía de negación, como la ciencia que no se realiza ni en la escuela ni en la familia. Tiene una orientación finalista, primordialmente hacia la juventud, enfocándola como "Pedagogía de la necesidad", por la que Alemania podría restaurarse de los problemas sociales, siendo sus objetivos la prevención y la profilaxis, como forma de solucionar los problemas sociales de la juventud.

\footnotetext{
Millán Arroyo, “¿Qué es la Pedagogía Social?”. Bordón, No. 257, 37 (1985), 208 s.

Arroyo, “¿Qué es la Pedagogía Social?”.

23 Herman Nohl (1879-1960), alemán, discípulo de Dilthey, iniciador de la Pedagogía como "Ciencia del espíritu", uno de los primeros representantes del "movimiento de renovación pedagógica". Su pedagogía parte del propósito de captar metódicamente la realidad educativa mediante el método histórico-hermenéutico, cuestión que fue bastante cuestionada debido a su escasa base empírica. Junto a Gertrud Bäumer contribuye al nacimiento del "movimiento pedagógico social" (sobre 1920), y especialmente en la consolidación de la perspectiva teórica-práctica de la PS.

24 Gertrud Bäumer (1873-1954), alemana, Consejera de Política Social de la República de Weimar, es discípula de Nohl, publica el V volumen del Manual de Pedagogía Social, editado por Nohl y Pallat. Considera que la PS es una tarea educativa, social y estatal, en tanto que se realiza fuera de la escuela (Pérez Serrano, 2002).

25 Wilhelm Dilthey (1833-1911), (citado por Radl, 1984:23).

26 Winfried Böhm, "La Pedagogía Social en Alemania" en Nuevos retos de la Pedagogía Social: la formación del profesorado, coordinado por José Ortega. (Salamanca: Sociedad Ibérica de Pedagogía Social, 2002), 15-20.
} 
No obstante, quien desarrolla ampliamente este concepto es Gertrudes Bäumer, discípula de Nohl, que fue Consejera de Política Social en la República de Weimar. Para ella la PS no es una pedagogía marginal en el sentido de subsidiaria de la familia y la escuela, sino que supone el tercer polo educativo de la educación de los individuos, un "nuevo sistema, con nuevos entes e instituciones responsables, al cual se le asignan, de modo normal y no excepcional, determinadas funciones dentro del objetivo global de la formación de los jóvenes a cargo de la familia, la sociedad y el Estado"27. Como parece desprenderse de la cita, Bäumer concibe el concepto global de la asistencia educativa extraescolar proporcionada por la sociedad y el Estado, siendo éstas las responsables de normalizar y universalizar unas acciones educativas determinadas (servicios, agencias, instituciones, profesionales) que, junto con la familia y la escuela, atiendan las necesidades de formación.

Comienza así la consideración de la PS como "teoría y praxis del conjunto de actividades educativas fuera de la escuela", lo que representa ya un avance con respecto a las etapas anteriores. En síntesis, Nohl y Bäumer consolidaron teórica y prácticamente la PS y contribuyeron al nacimiento del Movimiento Pedagógico Social. La eclosión del Tercer Reich acabará con esta situación, contrarrestando toda iniciativa de tipo social. En este rápido repaso por los principales representantes de los orígenes de la Pedagogía Social, de acuerdo a Bedmar y Añaños ${ }^{28}$, se han ido perfilando dos corrientes que surgen inicialmente en Alemania. Cada una de ellas supone un análisis de la realidad y una toma de posición frente o ante ella, que está inevitablemente marcada por la representación que se hace de la propia realidad social. Una estaría encabezada por Natorp y otra por Nohl. Sin embargo, se considera -como el profesor Quintana señala ${ }^{29}$ - que Natorp en realidad define una Pedagogía Sociológica, una forma de concebir toda la Pedagogía y que su uso del término Pedagogía Social viene a provocar una mayor confusión en el ya difícil panorama epistemológico que rodea a esta disciplina.

\section{El regreso al pensamiento de Herman Nobl}

Tras la segunda guerra mundial y la caída del Tercer Reich, los problemas y situaciones carenciales aumentaron exponencialmente. El derribo del nazismo ocasionó una mirada hacia atrás y se volvió a descubrir el pensamiento y la práctica de Nohl y Bäumer. La PS se convierte en una pedagogía de la urgencia o

\footnotetext{
27 Arroyo, “¿Qué es la Pedagogía Social?”, 209.

28 Matías Bedmar, y Fanny Añaños Bedriñana, Introducción a la Pedagogía Social / Educación Social. Colección Educación Social No 1. (Granada: Grupo Editorial Universitario, 2006).

29 José María Quintana, Pedagogía Social.
} 
de la emergencia o en palabras de la profesora Torío en "cajón de sastre" 30 donde va a parar todo aquello que sobrepasa los límites de la escuela.

Así, en la República Federal Alemana se crearon instituciones para propiciar orientación y ayuda a la infancia y jóvenes; se construyeron residencias, aldeas infantiles SOS y aldeas juveniles, se desarrolló la legislación social y desde el punto de vista teórico comenzó a desarrollarse la Pedagogía Social Crítica liderada por Mollenhauer ${ }^{31}$. Mollenhauer ${ }^{32}$, basándose en esta Teoría Crítica de la Escuela de Franfurt, elaboró una Pedagogía Social Crítica hacia 1960, donde somete a cuestionamiento a la sociedad y revisa crítica y ampliamente la relación entre los problemas de la sociedad industrial y la educación que se viene dando, y dedica su atención a la forma en que se puede ayudar a los individuos a potenciar su conciencia y su propia responsabilidad para solucionar sus problemas.

Con estos planteamientos nacieron los principios fundamentales de la intervención en los problemas sociales desde el punto de vista de la Educación Social, a partir de los cuales se inició el camino de la liberación del oprimido y el de la eliminación de la dependencia producida por sistemas de beneficencia. En Latinoamérica, bajo estas influencias, surge una figura, junto a otras en distintos países, muy importante, Paulo Freire, filósofo y educador brasileño.

A mediados de siglo XX cobra importancia Mollenhauer, quien se distancia del enfoque sociologista de Natorp. Expone que "el término Pedagogía Social se ha introducido para designar un determinado ámbito de tareas e instituciones pedagógicas y la teoría relativa a las mismas. La PS abarca todas aquellas tareas educativas que se suscitan en los lugares conflictivos de la sociedad industrial y que en ésta han venido a hacerse necesarias como medios auxiliares particulares. En este sentido existe la PS sólo desde que se han sometido los sucesos sociales a una crítica pedagógica y se hizo evidente que las vías educativas tradicionales resultaban ya insuficientes para asegurar el proceso de desarrollo personal" 33 .

Según la profesora Montoya y otros ${ }^{34}$ Mollenhauer contribuye con su análisis a clarificar la diferenciación del la PS respecto al Trabajo Social, ya que

30 Susana Torío. Evolución y desarrollo de la Pedagogía Social en España. Hacia una pedagogía social en construcción. Recuperado en: http://www.pedagogiasocial.cl/DOCS/COPESOC/S_Torio. PDF.

31 Mollenbauer Klaus (1928-1998).

32 Mollenbauer Klaus (1959).

33 José María Quintana, Pedagogía Social, 23.

34 Josefa Magdalena Montoya, et al, Pedagogía Social. (Madrid: UNED, 2001), 30. 
éste patrocina la asistencia social a personas adultas, sin matices educativos en su actuación.

Las necesidades evidentes de la Segunda Guerra Mundial dieron lugar a ciertas actuaciones sobre los sectores sociales más deprimidos. De esta praxis se derivó la discusión científico-teórica, y aquí destaca el profesor Arroyo ${ }^{35}$ a los siguientes autores: Mollenhauer, Rünger, Furck, Rössner y Pfaffenberger. Los años setenta suponen ya una etapa de madurez de la Pedagogía Social alemana, coincidiendo con el establecimiento en Europa del Estado de Bienestar. La intervención de los/as pedagogos/as sociales se orienta hacia la asistencia preventiva, planificación, diagnosis, orientación, problemas de la infancia, formación extraescolar, educación de adultos, problemas comunitarios y de tiempo libre...

En síntesis, el nacimiento de la Pedagogía Social puede definirse como el resultado de contingencias históricas externas, junto a las internas, conducidas por ideas previas, discursos, relaciones de poder... y que marcan el devenir de dos corrientes diferenciadas que coexisten en sus orígenes como ciencia en la Alemania de mediados-finales del siglo XIX y que van a evolucionar y expandirse, con diversos giros, hasta nuestros días ${ }^{36}$.

La primera, fija su punto de referencia a una "Educación Social en, desde y por la comunidad", percibida ésta muy íntimamente vinculada a la vida cotidiana de la comunidad, sin que pueda darse una separación radical entre una y otra;

La segunda, centra su objeto en la "intervención educativa en una población determinada y diferencial', donde la Pedagogía Social se vuelca a un trabajo preventivo, minimizador o corrector de las causas de las problemáticas sociales, actuando directamente con los sujetos que las padecen.

Esta última corriente fue la que acabó imponiéndose en Alemania y, por extensión, en toda Europa, a la cual se le llamó también "pedagogía de los sujetos carenciales" "37 y se asoció su emergencia a una intervención subsidiaria del Estado.

Epistemológicamente, la relación entre la teoría y la práctica centra el interés. "El objeto de la teoría sociopedagógica no es tanto el hecho profesional en sí de un trabajador social, sino más bien el discurso y respectivamente la

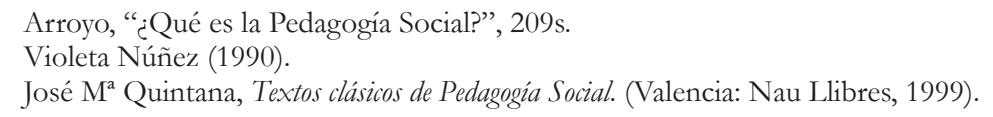


reflexión sobre esa acción". La teoría de la PS encuentra su punto de partida y su objeto en la identificación reflexiva de los problemas sociales y pedagógicos que surgieron a consecuencia de la revolución industrial. En la actualidad se presentan nuevos desafíos relacionados con los problemas sociales, pero se insiste en el carácter profesional de la prestación social moderna ${ }^{38}$.

Winfried Böhm ${ }^{39}$ destaca que el siglo XX se presenta como el siglo de la Pedagogía Social, en el que se observa un enorme auge de la disciplina, que se puede cursar en numerosas instituciones educativas superiores y que cuenta con más de un millón de personas dedicadas a ejercer trabajos sociales. Este desarrollo ha convertido el trabajo social en un sector económico propio, con una enorme profesionalización y gran academicismo. La disciplina se ha ido diferenciando de la Filosofía, especializándose en numerosas subdisciplinas, imponiéndose el problema de la identidad disciplinaria.

\section{El desarrollo de la PS en España}

La nueva dimensión y verdadero desarrollo de la PS en España se da en los años ochenta con la llegada de la democracia y el despliegue del Estado de Bienestar, que permiten aflorar demandas sociales y se suceden acontecimientos importantes en su consolidación, tal como mostramos a continuación. Algunos hitos en este camino son:

- 1981, realización de las I Jornadas Nacionales de PS y Sociología de la Educación $^{40}$, este evento se siguió llevando a cabo en años sucesivos.

- 1984, el profesor Quintana publica su Manual de Pedagogía Social, siendo la primera publicación que sistematiza esta ciencia en el país. Desde este momento -aunque realmente ya se había iniciado antes- comenzaron a aparecer libros de texto de Pedagogía Social que llevaban exactamente este título. Los más importantes y por orden de aparición fueron: José María Quintana (Ed. Dykinson), Antoni Petrus (Ed. Ariel), Paciano Fermoso (Ed. Herder), José Ortega (Ed. Ariel), Gloria Pérez (Ed. Narcea), J. Antonio Caride (Ed. Gedisa), Violeta Núñez (Ed. Santillana), Fanny Añaños (Ed. Gedisa)... Entorno a éstos y otros se ha ido produciendo más publicaciones y actividades científicas alrededor de la PS y de la ES.

38 Böhm, Winfried. “La Pedagogía Social en Alemania”. en Nuevos retos de la Pedagogía Social: la formación del profesorado, coordinado por José Ortega. (Salamanca: Sociedad Ibérica de Pedagogía Social, 2002), 16ss.

39 Winfried Böhm, catedrático de la Universidad de Würzburg, Alemania, en su ponencia "La Pedagogía Social en Alemania”, XVII Congreso de Pedagogía Social celebrado en Salamanca en 2002.

40 I Jornadas Nacionales de Pedagogía Social y sociología de la Educación, llevado a cabo en Sevilla en 1981, auspiciado por el ICE y la Univ. Sevilla. 
- $\quad$ 1985, se reconoce la PS en la sección científica de la Sociedad Española de Pedagogía ${ }^{41}$.

- $\quad$ 1986, se inicia la publicación de la Revista Interuniversitaria de PS ${ }^{42}$.

- $\quad$ 1991, se aprueba la Diplomatura ${ }^{43}$ en Educadora Social (RD 1420/1991, 30 de agosto, BOE 10 octubre ${ }^{44}$. Una vez insertada, estos estudios, la asignatura de Pedagogía Social se convirtió en un elemento básico en la formación de los educadores sociales.

- 2000, creación de la Sociedad Ibérica de PS, y desde el 2003 pasa a ser Sociedad Iberoamericana de PS ${ }^{45}$.

Hoy, La PS y la ES continúa fortaleciéndose y abriendo caminos de profundización y nuevos ámbitos que requieren de su intervención/acción. Los Educadores Sociales han reforzado su organización llegando a crear Colegios Profesionales en diversas Autonomías del Estado y se han dotado de un Código Deontológico ${ }^{46}$ para guiar su acción profesional.

\section{Corrientes actuales}

Indagando en el panorama actual, encontramos tres orientaciones principales en el continente europeo, según las cuales se han ido configurando el desarrollo disciplinar, éstas son ${ }^{47}$ :

1) Centroeuropeay germánica, gestada en Alemania, con influencia en algunos países del Este, en las penínsulas Itálica e Ibérica y, más recientemente en Latinoamérica. Sus inicios son idealistas y conceptualistas, con una vinculación

$41 \quad$ El 18 de Enero de 1985, se crea oficialmente la "Sección Cientifica de Pedagogía Social". Se trata de una nueva sección en la Sociedad Española de Pedagogía, cuyo objeto es ofrecer cobertura a la PS como disciplina científica y a la práctica profesional que de ella se deriva.

42 Hoy la revista, en su tercera época, se denomina Pedagogía Social. Revista Interuniversitaria. Constituye el referente idóneo de comunicación, confrontación e investigación, dedicada exclusivamente a este campo de trabajo.

43 Diplomatura es la titulación de educación superior que se obtiene tras realizar una carrera universitaria de tres años. Se trata de un grado académico donde se tiende a la especialización, de menor duración que la licenciatura, donde generalmente se imparten más cursos generalistas. Hoy este tipo de titulación se encuentra en extinción, tras la entrada en vigor de los nuevos títulos de grado, con una duración de 4 años, en el marco de la reforma del Espacio Europeo de Educación Superior y el Tratado de Bologna.

44 Este nuevo título universitario denominado Diplomado en Educación Social, con una duración de tres años, se procura implantar casi en todas las Universidades españolas. Este proceso fue muy desigual porque cada gobierno regional (Comunidad Autónoma) definió los momentos y condiciones de la implantación.

45 Esta nueva definición de la SIPS surge en el marco del XV III Seminario Interuniversitario de Pedagogía Social, llevado en Sevilla en 2003.

46 El Código Deontológico del Educador y Educador social, fue aprobada y asumida por todas las asociaciones de Educación Social en España (ASEDES), en Santiago de Compostela el año 2004.

47 José Ortega, "Realidades y desafíos". Cuadernos de Pedagogía, No 321, (2003): 52s 
entre Pedagogía Social y Educación Social, a la que considera su campo y objeto de estudio. Se inicia con Natorp y Nohl, con finalidades sociopolíticas y filosóficas. Se materializa en la "Pedagogía de la Urgencia", buscando en lo extraescolar nuevas oportunidades para el bienestar y la protección de la juventud. Reclama una integración dialéctica de su teoría y praxis en el crisol del Trabajo Social, diversificando tareas e instituciones y apostando por una visión crítico-emancipatoria, de la que fue un claro exponente Mollenhauer.

b) Anglosajona, con reflejo en EE.UU. y algunos países europeos. De cuño positivista, empirista y cientifista. Los análisis se hacen desde la Sociología de la Educación y desde la Psicología Social y las actuaciones preventivas, terapéuticas o de mejora son responsabilidad de los Servicios Sociales y de los trabajadores sociales, con una perspectiva asistencialista, con ayuda de otros profesionales. Raramente se habla de Pedagogía y menos de Pedagogía Social, aunque cada vez es más frecuente que lo educativo participe en el Trabajo Social.

c) Francófona, con influencia también en varios países europeos. De tradición racionalista, otorgó gran importancia a los análisis políticos y sociológicos del sistema escolar y la educación institucionalizada, con especial énfasis en el activismo pedagógico, en la democratización de la enseñanza, en la educación cívica, etc., primero a través de la "Educación Popular" y después de la "Animación Sociocultural". Evolucionó desde planteamientos benéficoasistenciales hacia los enfoques de naturaleza psicoeducativa y pedagógica, que desembocan en diversas iniciativas formativas, profesionales y asociativas.

Este esquema es clarificador en el sentido que presenta las diferencias entre las distintas orientaciones, aunque el análisis de la realidad nos permite observar que en ocasiones se dan al tiempo distintas orientaciones en una misma institución o en la puesta de marcha de un proyecto socioeducativo. Como ejemplos ilustrativos podemos citar los enfoques asistencialistas, de carácter benéfico o caritativo, de determinadas instituciones, que han evolucionado más adelante hacia actuaciones profesionalizadas, integradas en las políticas de los Servicios Sociales. Por otra parte, en centros o territorios se llevan a cabo actuaciones de urgencia, para resolver problemas puntuales y al mismo tiempo se diseñan y ejecutan planes de animación sociocultural y desarrollo comunitario a medio y largo plazo.

\section{Aproximación conceptual y proyección de la PS y de la ES}

La Pedagogía Social_en España se visibiliza en los años ochenta. El profesor Quintana (1983) sitúa la disciplina dentro las Ciencias de la Educación, y a su vez, en el marco de la Pedagogía Especial y, entre las Ciencias Actuales o Práxicas. 
La diferencia fundamental de esta ciencia con las otras ciencias pedagógicas es que mientras la Pedagogía reflexiona sobre el hecho educativo, la PS no se limita a la reflexión o estudio teórico, sino da un paso más, indaga en la realidad, se dirige a la acción para abordarla (ES) y, es el compromiso hacia la acción, dentro de una realidad social, el elemento diferenciador.

Llegados a este punto es conveniente definir qué es la PS y qué es la ES. Con frecuencia se emplean indistintamente, pero es oportuno aclarar que la PS es una ciencia y que la ES constituye su ámbito de intervención.

La $P S$ es un campo de conocimiento pedagógico teórico, una disciplina científica - académica, una metodología... en constante redefinición en función de cada contexto, momento, necesidad, etc., que tiene como objeto de estudio una práctica educativa que denominamos Educación Social, ejercida fundamentalmente fuera del marco escolar, aunque en los últimos años se evoca y trabaja, también, en y desde la escuela.

Por otro, tiene el compromiso por incidir en el cambio social, en la mejora de las condiciones de las personas y grupos específicos en situaciones de dificultad, conflicto o riesgo y/o de la población en general ("normalizada" o "integrada") en una sociedad tan compleja y cambiante, especialmente cuando resultan insuficientes las vías educativas tradicionales, para la participación, prevención, formación, comunicación, integración... Se encuentra amparada en los derechos humanos, abarcando todo el período de la existencia humana, desde la perspectiva de la educación a lo largo de la vida ${ }^{48}$. Del mismo modo, es el marco referencial que da sentido a la dimensión profesional de la Educación Social.

En cambio, la ES es una forma de educación, que, a su vez, es el objeto y ámbito de la $\mathrm{PS}^{49}$. La ES sería el fenómeno, la realidad, la praxis y la acción, que se encuentra contextualizada, de acuerdo a la coyuntura en la que se presentan ${ }^{50}$ participa la conciencia política, representa un factor de cambio social... Es también hoy una carrera universitaria y campo profesional ejercida por los/ as educadores/as sociales, erigiéndose en la opción de mayor preferencia de acceso universitario en el área educativa y que, cada vez, se va consolidando en el mercado de trabajo, donde los colegios profesionales de educadores sociales tienen un papel destacado.

48 José Ortega, "la educación a lo largo de la vida: La educación social, la educación escolar, la educación continua... todas son educaciones formales". Revista de Educación, No. 338 (2005), pp. 167-175.

49 José Ortega, "Realidades y desafíos".

50 Luis Pantoja, y Fanny Añaños-Bedriñana. "Actuaciones socioeducativas con menores vulnerables, en riesgo, relacionados con las drogas. Reflexiones críticas". Pedagogía Social. Revista Interuniversitaria, No 17, (2010): 109-122. 


\section{Ámbitos de la PS y de la ES}

Los ámbitos considerados pilares o básicos tradicionales, tampoco son unánimes. De ellos, la educación especializada, la animación sociocultural, la educación de adultos y, la educación laboral-ocupacional, se visibilizan como tales. Los ámbitos, escenarios o campos de la PS-ES en los que se desenvuelven son sumamente amplios y diversos, donde los distintos autores/as y corrientes, en su interior, hacen diferentes clasificaciones, teniendo como base clasificaciones de acuerdo a los espacios formales institucionales o fuera de la escuela, según la tipología de intervención, de la población, de equipamiento, etc. ${ }^{51}$.

Por ejemplo una clasificación normativa es la que establece la titulación ${ }^{52}$ centrada en campos como: "La educación no formal, educación de adultos, inserción social de personas inadaptadas y minusválidos, asimismo la acción socio-educativa". Una perspectiva que se queda muy limitada y con enfoques más bien tradicionales. Hoy este título ha dado paso a las nuevos Grados en Educación Social, tienen una duración de 4 años.

Es evidente que estos espacios se definen y redefinen de acuerdo al contexto, en un proceso continuo de construcción. A partir de una amplia revisión bibliográfica y reflexiones propias se plantea el siguiente cuadro:

Tabla No I: Campos, ámbitos o escenarios de la Pedagogía y de la Educación Social

\begin{tabular}{|c|c|}
\hline Campos genéricos & Campos Específicos \\
\hline Educación especializada & $\begin{array}{c}\text { Marginación / exclusión, } \\
\text { Pobreza y desigualdad social, } \\
\text { Inadaptación, } \\
\text { Delincuencia, } \\
\text { Corrupción, } \\
\text { Conflicto social, } \\
\text { Medio Penitenciario, } \\
\text { Transeuntismo (calle), } \\
\text { Prostitución, } \\
\text { Violencia y maltrato, } \\
\text { Discapacidad, } \\
\text { Discriminación de género, } \\
\text { Minorías étnicas, } \\
\text { Fenómenos migratorios, } \\
\text { Adicciones y Toxicomanías (drogodependencias), } \\
\text { Menores vulnerables (en riesgo, desamparo o en conflicto), etc. }\end{array}$ \\
\hline
\end{tabular}

51 Fanny Añaños (2010)

52 Real Decreto 1420/1991 sobre Título Universitario de Diplomado en Educación Social. 


\begin{tabular}{|c|c|}
\hline \multirow{4}{*}{ Animación socioeconómica } & Formación laboral y ocupacional, \\
& Inserción socio-laboral, \\
& Cooperación para el desarrollo, \\
Desarrollo comunitario, \\
Turismo social y ecológico, etc.
\end{tabular}

Fuente: Añaños, F. (2012)

La tabla no sólo categoriza las áreas o campos fundamentales de la PS y de la ES, sino que las redefine, a tenor de las nuevas reflexiones y propuestas tanto en el ámbito teórico como desde la praxis. Sin embargo, existen limitaciones puesto que, debido a la complejidad de los hechos, fenómenos, personas o grupos, muchas de las áreas pueden solaparse, situarse dentro o en marco de otros o ubicarse en varios; encontrándonos ante la estrecha interrelación de los elementos, por tanto requiere y es necesario un abordaje integral e interdisciplinar.

\section{CONCLUSIÓN}

La Pedagogía Social (PS), desde el principio, más allá de las corrientes, evoluciona como un saber práctico y saber teórico; su ejercicio da lugar a la profesión llamada Educación Social (ES), cuya matriz disciplinar, la ciencia y la materia de enseñanza es la PS.

En los procesos de intervención educativa, propios de la PS y la ES, hay un principio paradigmático que afirma que antes de actuar es necesario conocer (análisis de la realidad). Sólo a partir de este conocimiento se pueden 
plantear con sentido realista y respetuoso los cambios a lograr, las estrategias para conseguirlos, la duración del proceso de intervención, los instrumentos a emplear, los indicadores de evaluación, etc.

No obstante, la educación y especialmente la ES, tal como se entiende en su sentido teórico y práctico, tampoco puede encerrarse en los límites que le marcan la realidad o el postmodernismo y la globalización. Es cierto que la PS normativa ordena que primero se debe diagnosticar la situación antes de intervenir educativamente, pero no es menos cierto que ese principio normativo tiende a encerrar a la educación en unos límites impuestos que no tienen por qué ser buenos en su cabalidad. Es en este contexto en el que afirmamos que la PS debe ser una especie de metateoría, con un sentido de superación de los límites de la realidad, sobre todo cuando se trata de intervenciones educativas dirigidas a individuos o grupos que viven bajo los efectos abrumadores y salvajes de las nuevas formas de organización mundial, ambientes desestructurados, la pobreza o la exclusión...

La acción que presta la PS a los individuos en estado de necesidad en esta sociedad postmoderna es sólo el principio de un camino de liberación sobre la base de su propia dignidad humana, pero nunca el final ni la meta definitiva. Ya es hora de someter a un verdadero análisis crítico la valoración excesiva de conceptos tales como adaptación, reinserción, normalización y otros más que han venido considerándose como los objetivos per se de la ES.

\section{FUENTES}

Real Decreto.1420/1991, que establece el título universitario de Diplomado en Educación Social. BOE de 10 de octubre de 1991.

CO.PE.SO. Centro de documentación del Colectivo en Pedagogía Social. http://www. pedagogiasocial.cl/index.html

EDUSO. Portal de Educación Social. http://www.eduso.net/

\section{REFERENCIAS}

Añaños, Fanny. "Violencias y exclusiones en el medio penitenciario. Enfoque socio-educativo y de la paz.” Convergencia, No 59, (2012), 13-41.

Añaños, Fanny (Coord.). Las mujeres en las prisiones. Educación Social en contextos de riesgo y/ o conflicto. Barcelona: Gedisa, 2010.

Arroyo, Millán. “¿Qué es la Pedagogía Social?”. Bordón, No. 257, 37 (1985): 203-215. 
Bedmar, Matías y Fanny Añaños Bedriñana. Introducción a la Pedagogía Social / Educación Social. Colección Educación Social Nº 1. Granada: Grupo Editorial Universitario, 2006.

Böhm, Winfried. "La Pedagogía Social en Alemania". En Nuevos retos de la Pedagogía Social: la formación del profesorado, coordinado por José Ortega. Salamanca: Sociedad Ibérica de Pedagogía Social, 2002, 15-20.

Blanco, R. Teoría de la Educación (2 vol). Madrid: Librería y Casa Editorial de Hernando (1985).

Caride, J. Antonio. "La Pedagogía Social en España". En La educación en tiempos de incertidumbre: la respuesta de la Pedagogía Social coordinado por Violeta Núñez. Barcelona: Gedisa, 2002, 81-112.

Dilthey, Wilhelm. Fundamentos de un sistema de pedagogía. Buenos Aires: Losada, 1965.

Durkheim, Emile. Educación y Sociología. Barcelona: Península, 1996.

Fermoso, Paciano. “¿Pedagogía Social o Ciencia de la Educación Social?” Pedagogía Social. Revista Interuniversitaria, No. 10, segunda época, 2003: 61-84.

Luzuriaga, Lorenzo. Pedagogía Social y Política. Buenos Aires: Losada, 1968.

Mollenhauer, Klaus. Zur Bestimmung von Socialpädagogik und Socialarcbeit in der Gegenwart. Beltz: Weinheim, 1966.

Montoya, Josefa Magdalena, $\mathrm{M}^{\mathrm{a}}$ Paz Lebrero y José M $\mathrm{M}^{\mathrm{a}}$ Quintana. Pedagogía Social. Madrid: UNED, 2001.

Moreno Chávez, Jorge Alfonso. Sociología Jurídica a distancia. Managua: Universidad Centroamericana, 2010.

Natorp, Paul. Pedagogía Social. Teoría de la educación de la voluntad sobre la base de la comunidad. Madrid: La Lectura, 1913 [Edición de (2001). Madrid: Biblioteca Nueva].

Nöhl, Herman. Aufgaben und wege der so rial pádagogik. Weinheim: Beitz, 1965.

Núñez, Violeta. Pedagogía social: cartas para navegar en el nuevo milenio. Buenos Aires: Santillana, 1999.

Ortega, José (Coord.). Educación social especializada. Educación con menores en dificultad y en conflicto social. Barcelona: Ariel, 1999.

Ortega, José. "Realidades y desafíos". Cuadernos de Pedagogía, No. 321, (2003): 52-54.

José Ortega, "la educación a lo largo de la vida: La educación social, la educación escolar, la educación continua... todas son educaciones formales”. Revista de Educación, núm. 338 (2005), pp. $167-175$

Pantoja, Luis y Fanny Añaños-Bedriñana. "Actuaciones socioeducativas con menores vulnerables, en riesgo, relacionados con las drogas. Reflexiones críticas". Pedagogía Social. Revista Interuniversitaria, No. 17, (2010): 109-122.

Pérez Serrano, Gloria. Pedagogía Social - Educación Social. Construcción científica e intervención práctica. Madrid: Narcea, 2004.

Pérez Serrano, Gloria. "Origen y evolución de la Pedagogía Social”. Pedagogía Social. Revista Interuniversitaria, No. 9, segunda época, 2002: 193-231. 
Pérez Serrano, Gloria. "Presentación". Revista de Educación, No 336, monográfico sobre Pedagogía/Educación Social, 2005.

Petrus, Antonio (Coord.). Pedagogía Social. Barcelona: Ariel, 1997.

Quintana, José María. Pedagogía Social. Madrid: Dykinson, 1984.

Quintana, José María. "Pedagogía, Ciencia de la Educación y Ciencias de la Educación”. En Estudios sobre epistemología y Pedagogía Agustín Escolano y otros. Madrid: Anaya, 1983, 97-104.

Quintana, José Ma “La Pedagogía Social en Italia.” Pedagogía Social, No. 4, (1989): 7-26.

Quintana. José Ma. Textos clásicos de Pedagogía Social. Valencia: Nau Llibres, 1999.

Radl, Rita Ma " "Conceptos, teorías y desarrollo de la Pedagogía Social”. Bordón, No. 251, 36, (1984): 17-43.

Rodríguez Sedano, Alfredo. "Hacia una fundamentación epistemológica de la pedagogía social”. Educación y Educadores, Vol 9, No 2, (2006): 131-147.

Töennis, Ferdinand. Gemeinschaft und Gesellschaft, Grundbegriffe der Reinen Soziologie. Darmstadt: Wissenschaftliche Buchgesellschaft, 1963.

Úcar, Xavier. “El por qué y el pará qué de la Pedagogía Social”. En La pedagogía social en la sociedad de la información, coordinado por Jordi Planella y Jesús Vilar. Barcelona: Editorial UOC, 2006.

Añaños-Bedriñana, Fanny T. "Pensamiento y acción socioeducativa en Europa y España. Evolución de la pedagogía y educación social”. Revista Historia de la Educación Latinoamericana Vol. 14 No. 18, (2012): pp. 119 - 138. 